\title{
The modern view on the problem of joint pathology rehabilitation
}

\author{
Nailya Sheveleva, Larissa Minbayeva
}

Karaganda State Medical University, Department of Medical Rehabilitation and Physical Education, Karaganda, Kazakhstan

\begin{abstract}
The article provides literature review that reflect a modern view on the problem of articular pathology treatment and rehabilitation.

Step-by-step osteoarthritis management schemes, published in the leading recommendations (NICE, OARSI, HKOA) are presented. The results of modern clinical trials, systematic reviews and meta-analyzes on the use of various methods of physical therapy for joints diseases treatment from the standpoint of evidence-based medicine are analyzed. Etiopathogenetic and clinical substantiation for inclusion of physiotherapy measures in rehabilitation programs were given to help maximizing the impact on all links of the pathological process chain.

The use of different methods and techniques of physical therapy for osteoarthritis is currently debated, because of the contradictory literature data. Low level of evidence does not allow including physical therapy in the leading guidelines of osteoarthritis management. The reasons for low level of evidence might be small samples and insufficient degree of randomization in the majority of studies. Different sensitivity of patients to physical therapy and presence of associated diseases necessitate individualization of rehabilitation program that makes further large-scale assessment of impact of the physical factors difficult.

However, considering physical therapy infinite possibilities, scientists continue to actively explore, constantly improve and implement a lot of new, highly effective methods of physiotherapy in rehabilitation process of osteoarthritis, proving the prospects of this type of conservative therapy.
\end{abstract}

Keywords: osteoarthritis - physiotherapy - rehabilitation.

J Clin Med Kaz 2016; 2(40):6-13

Автор для корреспонденции: Минбаева Лариса Сергеевна, Карагандинский государственный медицинский университет. Адрес: г. Караганда, ул. Ержанова, 53-42. Тел.: +77053142637. E-mail: minbayeva_larissa@mail.ru.

БУЫН ПАТОЛОГИЯСЫ РЕАБИЛИТАЦИЯСЫНЫҢ МӘСЕЛЕЛЕРІНЕ ЗАМАНУИ КӨЗҚАРАС

Шевелева Н.И., Минбаева Л.С.

Қарағанды мемелекеттік медицина университеті, медициналық реабилитология және дене тәрбиесі кафедрасы, Қарағанды, Қазахстан

\section{Тұжырымдама}

Мақалада буын патологиясының реабилитациясы және емдеу мәселеріне замануи көзқарастың көрінісінің, әдебиеттік шолудың мәліметтері көрсетілген.

Остеоартроз менеджменті бойынша (NICE, OARSI, HKOA) жетекші нұсқауларда көрсетілген терапияның кезекті үлгісі жарықта көрсетілген. Дәлелді медицина ұстанынымен буын сырқаттарын емдеу үшін фризиотерапияның әр түрлі үлгісін, үлгілі шолу және метаанализді қолданумен замануи клиникалық зерттеулердің қорытындылары келтірілген. Патологиялық үдірістің барлық буындарына мейлінше тиімді әсер беру үшін, қалпына келтіру бағдарламасына физиотерапия құралын қосу үшін клиникалық және этиопатогенетикалық негіздеме берілген.

Әдебиетте көрсетілген мағлұматтар қарама қайшы болғандықтан, остеоартроз кезінде әр түрлі фризиотерапия үлгісін және әдісін қолдану қазіргі уақытта пікірталас тудырады. Дәлелдік деңгейдің төменділігі, остеоартрит менеджменті бойынша жетекші басшылыққа фризиотерапияны қосуға мүмкіндік бермеуі, бәлкім, көптеген зерттеулерді шағын сұрыптаудың рандомизациясының жеткіліксіз деңгейі болып табылады. Науқастардың физиотерапиялық әсерге әр түрлі деңгейдегі сезімталдығы және коморбидтті патологияның болуы реабилитация бағдарламасын даралау қажеттілігін негіздейді, бұл физикалық фактордың одан әрі ауқымды әрекетін айтарлықтай қиындатады.

Алайда, фризиотерапияның шексіз мүмкіндіктерін ескере отырып, реабилитациялық остеоартроз үдірісіне тұрақты жетілдіру және енгізу, физиотерапия әсер етуінің жаңа, жоғарғы тиімді әдістерін дәлелдей отырып консервативті емнің бұл түрінің келешегін ғалымдар белсенді түрде зерттеуде.

Түйін сөздер: остеоартроз - физиотерапия - реабилитация.

\section{СОВРЕМЕННЫЙ ВЗГЛЯД НА ПРОБЛЕМУ РЕАБИЛИТАЦИИ ПАТОЛОГИИ СУСТАВОВ}

Шевелева Н.И., Минбаева Л.С.

Карагандинский государственный медицинский университет, кафедра медицинской реабилитологии и физического воспитания, Караганда, Казахстан

\section{Резюме}

В статье представлен обзор литературных данных, отражающих современный взгляд на проблему лечения и реабилитации суставной патологии.

Освещены поэтапные схемы терапии, представленные в ведущих рекомендациях по менеджменту остеоартрозов (NICE, OARSI, HКОА). Приведены результаты современных клинических исследований, систематических обзоров и мета-анализов по применению различных методов физиотерапии для лечения заболеваний суставов с позиций доказательной медицины. Дано этиопатогенетическое и клиническое обоснование включения средств физиотерапии в программы реабилитации для оказания максимально эффективного воздействия 
на все звенья патологического процесса.

Применение различных методов и методик физиотерапии при остеоартрозе в настоящее время является дискутабельным, поскольку встречающиеся в литературе данные достаточно противоречивы. Низкий уровень доказательности, не позволяющий включить физиотерапию в ведущие руководства по менеджменту остеоартритов, является, вероятно, следствием проведения большинства исследований на малых выборках с недостаточной степенью рандомизации. Разная степень чувствительности пациентов к физиотерапевтическим воздействиям и наличие коморбидной патологии обуславливают необходимость индивидуализации программы реабилитации, что существенно затрудняет дальнейшую масштабную оценку действенности физического фактора.

Однако, учитывая безграничные возможности физиотерапии, ученые продолжают активно исследовать, постоянно совершенствовать и внедрять в реабилитационный процесс остеоартроза новые, высокоэффективные методы физиотерапевтического воздействия, доказывая перспективность этого вида консервативной терапии

Ключевые слова: остеоартроз - физиотерапия - реабилитация.

\section{Введение}

В соответствии с рекомендациями 2014 года Национального института здоровья и оказания помощи (NICE, Великобритания) под остеоартрозом понимают клинический синдром, который обусловлен наличием боли в пораженных суставах, сопровождающейся нарушением локомоторной активности, что приводит к снижению качества жизни [1]. При этом необходимо отметить, что согласно МКБ 10 M15-19 термины «остеоартрит», «артроз» и «остеоартроз» являются синонимами [2]. Определение остеоартроза как симптомокомплекса несколько отличается от предложенного Е.Л. Насоновым и соавт. (2008), где под указанной патологией подразумевается гетерогенная группа различных по этиологии заболеваний со сходными биоморфологическими и клинико-симптоматическими проявлениями и исходом. В основе развития заболевания лежит мультикомпонентное поражение суставных и периартикулярных структур (хрящ, субхондральная кость, синовиальная оболочка, связки, капсулы, околосуставные мышцы) [3].

Остеоартроз является самой распространенной формой поражения суставов и одной из ведущих причин инвалидизации в мире [1,3]. Согласно статистическим данным, в возрастной группе от 25 до 74 лет около 30\% населения имеют подтвержденную лучевыми методами диагностики суставную патологию [3]. Распределение в процентном соотношении выглядит следующим образом: 41\% - суставы кисти, 25\% коленные суставы, $11 \%$ - тазобедренные суставы [1]. Ведущее место по частоте обращаемости за медицинской помощью в структуре остеоартрозов занимает гонартроз, что составляет $13 \%[1]$.

Основным симптомом остеоартроза, который вынуждает пациента обратиться за специализированной помощью, является боль [4]. Часто выявляемое несоответствие тяжести клинических и рентгенологических проявлений заболевания объясняется особенностями формирования и иррадиации боли при патологии суставов [5]. Вовлечение в патологический процесс не только внутрисуставных и периартикулярных тканей, но и костно-мышечного и сухожильно-связочного аппарата всей нижней конечности обуславливают многофакторность формирования болевого синдрома и необходимость комплексного подхода к составлению программ реабилитации $[1,3]$.

Согласно литературным данным, основными целями терапии артрозов являются купирование миофасциального и мышечно-тонического болевых синдромов, замедление дегенеративно-деструктивных процессов посредством стимуляции микроциркуляции в субхондральных тканях, внутри - и периартикулярных структурах, что позволит повысить качество жизни пациентов [3,6].

Цель исследования: изучить современную литературу по современным видам реабилитации

\section{Виды реабилитационной помощи при па- тологиях суставов}

Охватить все этиопатогенетические звенья процесса с эффективным купированием клинической симптоматики позволяет индивидуализация реабилитационной программы остеоартритов (NICE, 2014), которая составляется с соблюдением принципа этапности лечебных и профилактических мероприятий [1]. В рекомендациях OARSI (2014), рабочая группа экспертов подтверждает необходимость персонифицированного подхода к терапии остеоартроза, что позволяет реализовать один из ведущих принципов современной медицины, который заключается в лечении конкретного пациента, а не заболевания [7,8].

На первый план при составлении лечебных программ для патологии суставов (NICE, 2014) выступают такие немедикаментозные методы, как физические нагрузки, средства физической и мануальной терапии, массаж [1]. Обязательным компонентом являются различные средства ортопедической коррекции (специализированная обувь, стельки, ортезы и прочее) и, при необходимости, вспомогательные устройства (трость, палки для скандинавской ходьбы) [1,7]. Включение в программу лечения пациентов с остеоартрозом лекарственной терапии осуществляется в случае недостаточной эффективности нефармакологических средств [1]. Изолированное применение лекарственных веществ не обеспечивает стойкий терапевтический результат, так как не создает условий для облегчения функционирования суставов.

Проведенные исследования подтверждают эффективность применения консервативных методов терапии для купирования клинической симптоматики остеоартроза и улучшения функциональной активности пораженных суставов $[1,3,6,9]$, однако количество хирургических вмешательств по замене пораженных остеоартритом суставов продолжает неуклонно увеличиваться [1]. Это может свидетельствовать о недостаточной эффективности нехирургических средств лечения начальных стадий заболевания [4], что приводит к закономерному увеличению количества запущенных случаев, когда единственно эффективным остается радикальное воздействие. Около $20 \%$ хирургических вмешательств не дают удовлетворительных результатов [1], поэтому поиск результативных консервативных методов лечения артрозов по-прежнему остается актуальным.

Разнообразие методов, используемых в современной физиотерапии, позволяет воздействовать на все этиопатогенетические и клиникосимптоматические звенья патологического процесса с учетом коморбидных заболеваний, широко представленных у пациентов, страдающих остеоартрозом [8]. Включение физиотерапевтических средств в программу реабилитации 
артрозов направлено на достижение анальгетического, противовоспалительного и репаративно-регенеративного эффектов, восстановление функциональной активности пораженных суставов и, как результат, повышение качества жизни пациентов [6]. R. Brakke и соавт. (2012) отмечают, что большую вероятность возникновения положительного ответа на применение методов физиотерапии для лечения остеоартроза имеют пациенты с легкими формами заболевания (одностороннее поражение, наличие клинической симптоматики менее 1 года, тест 40-метровой ходьбы менее 29,5 сек) и оценкой боли по 10-ти балльной шкале в 6 баллов [10].

Несмотря на широкий спектр физиотерапевтических методов лечения остеоартроза, наибольшее количество исследований приходится на чрезкожную электронейростимуляцию (ЧЭНС), нейромышечную электростимуляцию (НМЭС), ультразвуковую терапию и бальнеотерапию. Другие методы физиотерапии, возможно вследствие достаточно высокой стоимости оборудования, комплектующих и, соответственно, непосредственно процедур, остаются труднодоступными широким массам, что затрудняет проведение дальнейшей масштабной оценки факторов. Также, возможным вариантом отсутствия результатов исследований по применению многих физиофакторов в англоязычных базах данных является их ограниченное использование в медицине за пределами стран СНГ [11]. Разная чувствительность пациентов к идентичному физиотерапевтическому воздействию, наличие широкого спектра сопутствующих заболеваний и проведение большинства исследований на малых выборках обуславливают низкий уровень доказательности физиотерапии, что ограничивает возможность ее включения в ведущие руководства по менеджменту остеоартритов, однако, не опровергает высокую эффективность у отдельных больных. Так, при составлении руководства по лечению остеоартроза коленных и тазобедренных суставов (НКОА) W.F. Peter и соавт. (2011) отметили, что бальнео- и гидротерапия, теплолечение, ЧЭНС и пассивная разработка суставов хоть и не обладают доказанной эффективностью, могут быть использованы с терапевтической целью. Согласно НКОА, применение при остеоартрозе массажа, ультразвуковой и электротерапии, a также электромагнитных полей и низкоинтенсивной лазерной терапии (НИЛТ) не является обоснованным [12]. В соответствии с рекомендациями Международного научноисследовательского общества по проблемам остеоартрита (OARSI) 2014 года, эффективность применения ЧЭНС и ультразвуковой терапии при остеоартрозе не доказана [7], и отсутствует у НМЭС. Однако назначение физиотерапии на стационарном и поликлиническом уровнях включено в последние клинические протоколы диагностики и лечения Министерства Здравоохранения Республики Казахстан (М3 РК) при гонартрозе и коксартрозе $[13,14]$. В соответствии с вышеуказанными протоколами М3 РК (2014), при артрозе височно-нижнечелюстного сустава рекомендовано применение УВЧ - терапии, локального ультрафиолетового облучения суставов, электрофореза и ультразвуковой терапии. Согласно разработанным в 2012 году стандартам первичной медико-санитарной помощи Министерства Здравоохранения Российской Федерации (ПМСП МЗ РФ), СМТ-терапия, электрофорез лекарственных препаратов и миостимуляция рекомендуются для лечения артроза лучезапястного сустава и мелких суставов кисти, стопы, поражениях локтевого сустава $[15,16]$. Электрофорез и магнитотерапия включены в стандарт ПМСП МЗ РФ (2012) для коксартроза, гонартроза и сходных с артрозом коленных суставов клинических состояний [17-19].

Учитывая разнообразие арсенала средств физиотерапевтического воздействия и возможность оказания комплексного воздействия с минимальными побочными эффектами, ученые продолжают активно исследовать, постоянно совершенствовать и внедрять в реабилитационный процесс остеоартроза новые, высокоэффективные методы и методики физиотерапии.

Сцельюкомплексноговоздействиянабольивоспаление, оказания нейромиостимулирующего, вазоактивного и регенеративного воздействия, рекомендуется назначение магнитотерапии. Высокоинтенсивную импульсную магнитотерапию (400-800 мТл, 5-10 мин/сустав, 10 процедур) для лечения артрозов рекомендует А.А. Ушаков (2013) [20]. G.L. Bagnato и соавт. (2015) успешно применяли пульсирующие электромагнитные поля (ПЭМП) в терапии гонартрозов при проведении двойного слепого, плацебоконтролируемого, рандомизированного клинического исследования (РКИ). В результате терапии наблюдалось уменьшение выраженности боли по визуальной аналоговой шкале (ВАШ) (-0,73 (95\% доверительный интервал (ДИ) от - 1,24 до - 0,19), улучшение показателей по Western Ontario and McMaster University Osteoarthritis Index (WOMAC) (-0,34 (95\% ДИ от 0,85 до 0,17), 26\% пациентов смогли отказаться от НПВС и обезболивающих препаратов [21]. H. Wuschech и соавт. (2015) в проспективном, плацебо-контролируемом, двойном слепом исследовании наблюдали «очень хороший» результат (по оценке пациентов) применения ПЭМП (412 Гц, плотность потока мощности 105 мТл на глубине 1 см, дважды в день по 5 мин в течение 18 дней) у 29,5\% пролеченных с гонартрозом, 27,3\% пациентов оценили результат лечения как «хороший». Авторы отметили достоверное снижение боли $(\mathrm{p}<0,001)$, уменьшение скованности в суставах $(\mathrm{p}=0,032)$ и увеличение ежедневной функциональной активности $(\mathrm{p}=0,005)$ по WOMAC [22]. Согласно же обзорному исследованию S. Li и соавт. (2013), применение электромагнитных полей не способствует статистически значимому улучшению функциональной активности (средняя разница 4,55; 95\% ДИ от -2,23 до 11,32; абсолютное улучшение - 4,55\%) по WOMAC и улучшению показателей качества жизни (стандартизированная средняя разница 0,$09 ; 95 \%$ ДИ от -0,36 до 0,54; абсолютное улучшение 0,09\%). Статистическая выкладка по обезболивающему действию электромагнитных полей выглядела следующим образом: средняя разница 15,$10 ; 95 \%$ ДИ от 9,08 до 21,13; абсолютное улучшение - $15 \%$ [23].

Магниторезонансную терапию (МРТ) применяли N. Goksen и соавт. (2016) у 97 пациентов с легкой и средней степенью гонартроза, отметив отсутствие преимуществ назначения метода (-2,6 - боль по ВАШ; -2,09 - боль по WOMAC; -1,81 - скованность по WOMAC; -1,96 - физическая шкала по WOMAC) в сравнении с плацебо через 2 недели (-1,6 - боль по ВАШ; -1,91 - боль по WOMAC; -1,27 скованность по WOMAC; -1,54 - физическое состояние по WOMAC) [24].

Г.Н. Пономаренко (2005) отмечает, что репаративнорегенеративное действие высокоинтенсивной высокочастотной магнитотерапии обусловлено 
равномерным локальным нагревом тканей сустава на 2-40С на глубину до 8-12 см (13,56, 27,12 и 40,68 МГц; мощность от 20 Вт; тепловая дозировка; по 15 мин; 12 процедур) [25].

Согласно данным А.А. Ушакова (2013), выраженным противовоспалительным действием обладают низкоинтенсивная УВЧ-терапия (27,12 и 40,68 МГц, мощность 20-30 Вт, слаботепловая дозировка, 5-12 мин, 8-12 процедур) и высокоинтенсивная сантиметроволновая терапия (2450МГц, 40-60Вт, среднетепловая дозировка, 15-20 мин, 12-15 процедур). Для стимуляции метаболических процессов в суставе применяется дециметроволновая терапия (40-50 Вт, 10-15 мин, 10 процедур) [20].

Широко применение нашли в терапии патологии суставов методы фототерапии, такие как лазерное излучение (гелий-неоновый лазер (0,5-2 мВт/см2, 5-8 мин, 15 процедур), инфракрасный лазер (1000-1500 Гц, 6-10 Вт в импульсе, 6-8 минут, 10 процедур)), облучение пораженных суставов инфракрасным и поляризованным светом [20]. Пономаренко Г.Н. (2005) предлагает облучать инфракрасным лазером (30-100 мВт; частота модуляции 100 Гц, с 4-5-й процедуры - 10 Гц; по 2 мин на точку, 8-10 мин ежедневно, 15 процедур) проекционные паравертебральные зоны для снижения болевой чувствительности, которое достигается посредством блокирования С-афферентной импульсации. В области болевой зоны при остеоартрозе - локальное СУФоблучение в эритемной дозе [6]. Д.Б. Кульчицкая и соавт. (2015) с успехом применяли высокоинтенсивное лазерное излучение (ВИЛИ) с целью уменьшения воспалительных процессов в коленных суставах, уменьшения выраженности деструктивных процессов и улучшения локомоторной активности посредством усиления локального кровообращения [26]. Статистически значимое уменьшение выраженности боли по ВАШ $(\mathrm{p}<0,001)$ при применении ВИЛИ у пациентов с остеоартрозом выявили N. StiglićRogoznica и соавт. (2011) [27]. Kheshie A.R. и соавт. (2014) проводили сравнительную оценку комплексного применения физических упражнений с низко- и высокоинтенсивным лазерным излучением у пациентов с гонартрозом в рандомизированном контролируемом исследовании. Авторы установили большую эффективность комплекса, состоящего из упражнений и ВИЛИ $(p<0,05)$, отмечая также положительную динамику в группе, где применяли физически нагрузки и НИЛИ в сравнении с плацебо [28]. Kędzierski T. и соавт. (2012) проводили сравнительную оценку применения низкоинтенсивной лазерной терапии (НИЛТ) и низкочастотной чрезкожной электронейростимуляции (ЧЭНС) у пациентов с гонартрозом. Авторы отметили более высокую эффективность НИЛТ в отношении купирования болевого синдрома, однако статистически значимых различий по показателям функционирования суставов на фоне применения НИЛТ и ЧЭНС выявлено не было [29]. Jan M. Bjordal и соавт. (2007) при проведении систематического обзора и мета-анализа РКИ у пациентов с остеоартрозом коленных суставов выявили клинически значимый обезболивающий эффект применения ЧЭНС (в том числе интерференционных токов), электроакупунктуры и НИЛТ, что составило по ВАШ 18,8 мм (95\% ДИ: от 9,6 до 28,1), 21,9 мм (95\% ДИ: от 17,3 до 26,5) и 17,7 мм (95\% ДИ: от 8,1 до 27,3) соответственно, в сравнении с плацебо-контролем [30]. Также, в практике лечения остеоартроза ЧЭНС применяли Cherian J.J. и соавт. (2015) для купирования болевого синдрома в коленных суставах.
Выраженный положительный эффект применения ЧЭНС способствовал уменьшению количества принимаемых обезболивающих препаратов у большинства пациентов [31]. Zeng С. и соавт. (2015) провели систематический обзор и сетевой мета-анализ группы РКИ по применению электрической стимуляции для купирования болевого синдрома при остеоартрите коленных суставов. Была проведена оценка 27 исследований по применению высокои низкочастотной чрезкожной электронейростимуляции (h-TENS и 1-TENS), нейромышечной электростимуляции (NMES), интерференционных токов (IFC), пульсовой электростимуляции (PES), неинвазивной интерактивной нейростимуляции (NIN). Согласно полученным результатам, более высокой эффективностью в отношении купирования болевого синдрома обладают интерференционные токи (в сравнении с контрольной группой стандартизированная средняя разница $(\mathrm{CCP})=2,06$ с 95\% ДИ от 1,1 до 3,19), однако, уровень доказательности метода был ограничен из-за гетерогенности групп обследуемых и недостаточно больших выборок. Несколько меньшим анальгезирующим эффектом, по данным исследования, обладает h-TENS [32]. Включать короткоимпульсную электроаналгезию (TENS) в программу лечения остеоартроза рекомендует Пономаренко Г.Н. (2016) (прямоугольные и треугольные моно- и биполярные импульсы, сериями по 20-100 импульсов; 5-10 мА при частоте 40-200Гц и 15-30 мА при частоте 2-12 Гц) [33]. Нейромышечную электростимуляцию (НМЭС) на m. quadriceps, учитывая развитие атрофии и слабости четырехглавой мышцы бедра при остеоартрите коленных суставов, применяли M.A. Vaz и соавт. (2013). Авторы наблюдали увеличение толщины латерального брюшка мышцы (от 12,6 до 14,2 мм) и длины мышечных пучков (до 24,6\%). Было отмечено, что НМЭС способствует увеличению силы мышц-разгибателей коленного сустава на 8\%, а также способствует снижению боли в суставах и повышению функциональной активности [34]. А.А. Ушаков (2013) предлагает применять электрофорез анестезирующих растворов новокаина и лидокаина на пораженный сустав (10-15 мА, 20-30 мин, 15 процедур) для уменьшения выраженности болевого синдрома [20].

Для усиления гемодинамики, трофических и обменных процессов в суставах назначаются диадинамотерапия (ДДТ) (двухполупериодный непрерывный (ДН) - 1мин, однополупериодный волновой (ОВ) - 6 мин (3 мин - в прямой полярности, 3 мин - в обратной), однополупериодный ритмический ток (ОР) - 2-3 мин; сила тока - до выраженной вибрации, ежедневно, 8-10 процедур), амплипульстерапия (CMT) (переменный режим, глубина модуляции 50\%, 80Гц, III и IV род работы по 5 мин, ежедневно, 10 процедур), интерференцтерапия (100 Гц, постоянная частота, по 2-3 мин, затем ритмическая частота 25-100 Гц до ощущения вибрации, 10-12 мин, ежедневно или через день, 10-15 процедур), местная дарсонвализация (110 кГц, 8-10 мин, 1012 процедур) [25]. Достижение анальгетического эффекта процедур электротерапии обеспечивается при следующих параметрах: для интерференцтерапии - 50-70 Гц, сила тока - до умеренной вибрации, продолжительности процедуры - 10-12 мин; для ДДТ - двухполупериодный волновой ток (ДВ) 2-3 мин, модулированный коротким периодом ток (КП) 4-6 мин со сменой полярности; для СМТ - 30-100 Гц, глубина модуляции 50-100\%, посылки импульсов по 2 с, ПН и ПЧ по 4-6 мин [33]. D.V. Babaskin и соавт. (2011) отмечают, 
что СМТ-форез фитопрепаратов позволяет уменьшить боль в коленных суставах и повысить их функциональную активность значительно эффективнее, чем изолированное или комбинированное с амплипульстерапией применение средств фармакологической коррекции [35].

Для воздействия на внутри- и околосуставные структуры с противовоспалительной, обезболивающей и дефиброзирующей целью применяют ультрафонофорез (0,20,4 Вт/см2, 5-8 мин/сустав, 15 процедур) обезболивающих, НПВС- и хондроитин сульфатсодержащих препаратов [20]. Согласно Г.Н. Пономаренко (2005), повысить эффективность ультразвукового воздействия в 1,5-2 раза возможно при проведении терапии через водную среду [25]. Также о высокой эффективности ультразвуковой терапии при остеоартрите коленных суставов говорят S.K. Yildiz и соавт. (2015), М.A. Yıldırıı и соавт. (2015) [36, 37].

A. Loyola-Sánchez и соавт. (2010) опубликовали данные систематического обзора с проведением мета-анализа по применению ультразвуковой терапии (УЗТ) в лечении гонартроза. Согласно анализу 6 небольших исследований, применение ультразвука способствует уменьшению болевого синдрома (95\% ДИ= -0,49 (-0,79; -0,18), $\mathrm{P}=0,002)$, формируется тенденция к улучшению самооценки физической активности (ССР (ДИ)=-0,54 (-1,19; 0,12), $\mathrm{P}=0,11)$ и показателей ходьбы (СРР (ДИ) $=0,81(-0,09 ; 1,72)$, $\mathrm{P}=0,08)$. Анализ отдаленных результатов (через 10 месяцев) 2-х исследований показал положительный эффект УЗТ в отношении боли (ССР (ДИ)=-0,77 (-1,15, -0,39), $\mathrm{P}<0,001)$, самооценки физической активности (ССР (ДИ)=-1,25 (-1,69, $-0,81), \mathrm{P}<0,001)$ и показателей ходьбы (ССР (ДИ) $=1,47(1,06$; 1,88), $\mathrm{P}<0,001)[38]$.

Эффективным в лечении остеоартрозов представляется применение бальнеотерапии [7, 25], однако, авторы отмечают необходимость проведения более масштабных исследований для повышения уровня доказательности результативности метода. Согласно Г.Н. Пономаренко (2005), сульфидные ванны (50-150 мг/л, 8-15 мин, 34-360С, через день, 10-14 процедур) способствуют стимуляции репаративно-регенеративных процессов в суставных структурах. Включение в программу лечения радоновых ванн (1,5-3,0 кБк/л, 36-370С, 12-15 мин, ежедневно или через день, 10-15 ванн) позволяет повысить сопротивляемость внутрисуставного хряща физическим нагрузкам [25]. При проведении сравнительной оценки эффективности сульфидных и не сульфидных ванн (три 20-ти минутных ванны в неделю, 10 недель, 37-390С), M. Branco и соавт. (2016) выявили достоверное уменьшение выраженности боли, улучшение показателей функциональной активности и снижение количества принимаемых обезболивающих препаратов в обеих группах обследуемых. Однако, в группе, где пациенты получали сульфидные ванны, результаты проведенной терапии были лучше и сохранялись на более длительный срок $(\mathrm{p}<0,001)$ [39]. А.Н. Разумов и соавт. (2015) проводили сравнительную оценку эффективности изолированного применения радоновых ванн и терапевтического комплекса из радоновых ванн и экстракорпоральной ударно-волновой терапии (ЭУВТ) у пациентов с остеоартрозом коленных суставов II-III стадии. В контрольной группе схема лечения состояла из лечебной гимнастики, магнитотерапии и приема нестероидных противовоспалительных препаратов. Согласно полученным данным, лучшие результаты в отношении купирования боли, восстановления функциональной активности и улучшения качества жизни в целом были получены в группе с комплексным применением радоновых ванн и ЭУВТ [40].

ЭУВТ является одним из актуальных, активно изучаемых методов современной физиотерапии, который широко применяется при заболеваниях опорнодвигательного аппарата. Положительное действие ударной волны на соединительнотканные структуры, костную, мышечную и хрящевую ткани [41-48] создает основательные предпосылки для включения ЭУВТ в программы лечения остеоартрозов, однако количество подобных исследований пока невелико. Эффективность ЭУВТ в терапии остеоартрозов отмечали Z. Zhao и соавт. (2013), Kim Jin-Hong и соавт. (2015) [49, 50]. Z. Zhaо и соавт. (2013) применяли ЭУВТ (4000 импульсов, 0,25 mJ/ $\mathrm{mm} 2$ еженедельно в течение 4-х недель) у 70 пациентов с остеоартрозом коленных суставов. В сравнении с плацебо, достоверное улучшение наблюдалось в отношении боли по индексу Лекена (Lequesne indices), WOMAC и по ВАШ (с 7,56 до 3,83; p<0,01) [49]. Kim Jin-Hong и соавт. (2015) обнаружили достоверное снижение боли по ВАШ на фоне применения средне- и низкоинтенсивной ударно-волновой терапии (с $6,10 \pm 1,26$ и 5,93 $\pm 1,15$ до $1,57 \pm 0,50$ и $1,90 \pm 0,71$ баллов соответственно) за 12-недельный период ( $<<0,001$ для временного эффекта, $\mathrm{p}<0,001$ для разноинтенсивных процедур). Показатели шкалы Roles and Maudsley score в обеих группах снизились с $3,23 \pm 0,73$ и $3,27 \pm 0,76$ до $1,10 \pm 0,31$ и $1,23 \pm 0,43$ соответственно $(\mathrm{p}<0,001$ для временного эффекта, $\mathrm{p}<0,05$ для межгрупповых взаимодействий). Снижение показателей по WOMAC составило с 57,63 $\pm 10,21$ и $56,90 \pm 11,44$ до $23,20 \pm 7,78$ и $33,33 \pm 7,03$ соответственно ( $<<0,001$ для временного эффекта, $p<0,001$ для межгрупповых взаимодействий). Индекс Лекена уменьшился с 14,9 $\pm 3,1$ и $14,5 \pm 3,5$ до 4,8 $\pm 1,5$ и 7,5 $\pm 2,2$ соответственно за период с 1 -й по 12-ю неделю ( $<<0,001$ для временного эффекта, $\mathrm{p}<0,001$ для межгрупповых взаимодействий) [50].

Шавианидзе Г.О. и соавт. (2006) применяли мышечную контрпульсацию (МКП) у пациентов с остеоартрозом суставов нижних конечностей с обезболивающей и противовоспалительной целями, а также для улучшения локомоторных функций и повышения мышечного тонуса. Авторы также отметили возможность потенцирования достигнутого положительного эффекта путем комбинирования МКП с радоновыми и йодобромными ваннами [51].

О пользе тепловых и холодовых воздействий при остеоартрозе говорят многие исследователи [11,20,25,53]. Положительный эффект нафталанотерапии, локальной криотерапии сухим холодным воздухом (-300С, 10-15 минут, 10 процедур) на пораженный сустав отмечает А.А. Ушаков (2013) [20]. Ежедневный криомасссаж льдом вызывает купирование болевого синдрома (OP=29\%) [11]. Для стимуляции анаболических и катаболических процессов в тканях суставов Г.Н. Пономаренко (2005) рекомендует использование комбинации пелоидотерапии и индуктотермии на уровне TX-LI (8-10 мин, через день, 180-200 мА). При применении грязевых аппликаций температура используемого пелоида должна составлять 42-44oС (15-20 мин для сульфидных грязей, 25-30 мин для сапропелевых и торфяных) [25]. G.O. Gungen и соавт. (2015) проводили сравнительную оценку эффективности грязевых аппликаций и теплолечения (hot pack) при гонартрозе. Через 3 мес. после проведенной терапии авторы обнаружили значительное снижение уровня uCTX-II $(\mathrm{p}<0,017)$. 
Значительно более выраженное уменьшение скованности суставов по WOMAC наблюдалось через $3 \mathrm{mec.} \mathrm{в} \mathrm{группе,}$ где применяли грязевые аппликации $(\mathrm{p}<0,05)$ [52]. В.Д. Сидоров и С.Б. Першин (2015) смогли на 33\% повысили эффективность реабилитационного курса остеоартроза коленных и тазобедренных суставов путем включения гипербарической газовой криотерапии. Авторами была отмечена более высокая клиническая эффективность метода в отношении коленных суставов, что составило 90\%, тогда как для тазобедренных суставов - 64\% [53].

Young Geun Park и соавт. (2013) провели сравнительное исследование по оценке эффективности курса вибрационного массажа и физических упражнений (самостоятельное выполнение в домашних условиях) с изолированным применением упражнений. Согласно полученным данным, боль, оцененная по Numeric Rating Scale (NRS) в обеих группах уменьшилась за период от момента начала терапии до 2-х месяцев после ее окончания с $3,91 \pm 1,22$ и $5,09 \pm 1,76$ до $2,46 \pm 1,81$ и 4,46 22,38 ( $=0,0401)$ соответственно. Значительных изменений по показателям физического функционирования по Korean Western Ontario McMaster score (KWOMAC) и по Lysholm Scoring Scale (LSS) $(\mathrm{p}=0,9670$ и $\mathrm{p}=0,9941$ соответственно) выявлено не было. Также авторы не обнаружили достоверного улучшения динамического баланса, изокинетической и изометрической силы четырехглавых мышц [54]. Несколько позже, P. Wang и соавт. (2016) получили результаты, доказывающие большую эффективность применения вибрационной платформы и физических упражнений для укрепления четырехглавой мышцы бедра, чем отдельного курса физических упражнений [55].

\section{Выводы}

Таким образом, согласно представленному обзору литературы, применение различных методов и методик физиотерапии при остеоартрозе является дискутабельным, поскольку встречающиеся в литературе данные достаточно противоречивы и не позволяют сформировать необходимый для обеспечения доказательной базы пласт данных. Стратегия и тактика лечения остеоартроза предусматривают комплексное воздействие на все этиопатогенетические звенья процесса и клиническую симптоматику заболевания для достижения максимально возможных результатов. Существующие на сегодняшний день методы лечения патологии суставов являются не достаточно эффективными, оказывают кратковременное действие, требуют постоянного контроля риска развития побочных эффектов и осложнений используемых методов.

Вышеперечисленное совершенствование делает актуальным лечебно-реабилитационных мероприятий при остеоартрозе, в частности физиотерапии, которые позволят повысить эффективность лечения, оптимизировать сроки реабилитации и повысить качество жизни пациентов.

\section{Литература}

1. National Clinical Guideline Centre. Osteoarthritis. Care and management in adults, National Institute for Health and Care Excellence (NICE) (Clinical guideline; no. 177), London (UK), 2014, 556 p.

2. Mezhdunarodnaya statisticheskaya klassifikatsiya bolezney i problem, svyazannykh so zdorovyem (International Classification of Diseases and Related Health Problems) (MKB-10), Tom I (chast 2), Moskovskiy tsentr VOZ, M.:Meditsina, 2003,924 p.

3. Nasonov E.L., Nasonova V.A. Revmatologiya: natsionalnoye rukovodstvo (Rheumatology: national leadership), M.:GEOTARMedia, 2008, 573-588 p.

4. Sofat N. What makes osteoarthritis painful? The evidence for local and central pain processing, Rheumatology (Oxford), 2011, Vol. 50, pp. 2157-2165.

5. Doerti M. Klinicheskaya diagnostika bolezney sustavov, Mn.: Tivali, 1993, 144 p.

6. Ponomarenko G.N. Fizioterapiya: natsionalnoye rukovodstvo (Physiotherapy: national leadership), M.:GEOTAR-Media, 2009, $864 \mathrm{p}$.

7. McAlindon T.E., Bannuru R.R., Sullivan M.C. et. al. OARSI guidelines for the non-surgical management of knee osteoarthritis, Osteoarthritis and Cartilage, 2014, Vol. 22, No. 3, pp. 363-388.

8. Khitrov N.A. Osteoartroz. Sovokupnost klinicheskikh form i soputstvuyushchikh zabolevaniy (The totality of the clinical forms and related diseases), RMZh, 2015, No. 7, pp. 363.

9. Kon E., Filardo G., Drobnic M., et al. Non-surgical management of early knee osteoarthritis, Knee Surg. Sports Traumatol. Arthrosc., 2012, Vol. 20, pp. 436-449.

10. Brakke R., Singh J., Sullivan W. Physical Therapy in persons with osteoarthritis, PM\&R, 2012, Vol. 4, No. 5, pp. S53-S58.

11. Ponomarenko G.N., Kupriyanov A. Osnovy dokazatelnoy fizioterapii (Evidence-based physiotherapy), Kiyev, 2005,288 p.

12. Peter W.F., Jansen M.J., Hurkmans E.J. et al. Physiotherapy in hip and knee osteoarthritis: development of a practice guideline concerning initial assessment, treatment and evaluation, Acta Reumatol. Port., 2011, Vol. 36, No. (3), pp. $268-281$.

13. Klinicheskiye protokoly diagnostiki i lecheniya Ministerstva Zdravookhraneniya Respubliki Kazakhstan (Clinical protocols of diagnostics and treatment of the Ministry of Health of the Republic of Kazakhstan), Protokol №9, 2014.

14. Klinicheskiye protokoly diagnostiki i lecheniya Ministerstva Zdravookhraneniya Respubliki Kazakhstan (Clinical protocols of diagnostics and treatment of the Ministry of Health of the Republic of Kazakhstan), Protokol №17, 2015.

15. Prikaz Minzdrava Rossii ot 24.12.2012 №1503n «Ob utverzhdenii standarta pervichnoy mediko-sanitarnoy pomoshchi pri artroze luchezapyastnogo sustava i melkikh sustavov kisti, stopy» (On approval of the standard of primary health care with osteoarthritis wrist and small joints of hands, feet), 1012.

16. Prikaz Minzdrava Rossii ot 24.12.2012 №1474n «Ob utverzhdenii standarta pervichnoy mediko-sanitarnoy pomoshchi pri poliartroze (porazhenii loktevogo sustava)» (On approval of the primary health care standard in arthritis (defeat of the elbow)), 2012.

17. Prikaz Minzdrava Rossii ot 24.12.2012 №1498n «Ob utverzhdenii standarta pervichnoy mediko-sanitarnoy pomoshchi pri gonartroze i skhodnykh s nim klinicheskikh sostoyaniyakh» (On approval of the standard of primary health care in gonarthrosis and similar to clinical conditions), 2012. 
18. Prikaz Minzdrava Rossii ot 20.12.2012 №1108n «Ob utverzhdenii standarta pervichnoy mediko-sanitarnoy pomoshchi pri posttravmaticheskom koksartroze» (On approval of the standard of primary health care for post-traumatic coxarthrosis), 2012.

19. Prikaz Minzdrava Rossii ot 20.12.2012 №1132n «Ob utverzhdenii standarta pervichnoy mediko-sanitarnoy pomoshchi pri pervichnom koksartroze, revmatoidnom artrite, podagre s porazheniyem tazobedrennykh sustavov, osteonekroze i kistakh golovki bedrennoy kosti» (On approval of the standard of primary health care at the primary coxarthrosis, rheumatoid arthritis, heating with damage to the hip joint, osteonektroze and cysts of the femoral head), 2012.

20. Ushakov A.A. Prakticheskaya fizioterapiya: Rukovodstvo dlya vrachey (Practical physiotherapy: a guide for physicians), M.: MIA, 2013, $688 \mathrm{p}$.

21. Bagnato G.L., Miceli G., Marino N. et al. Pulsed electromagnetic fields in knee osteoarthritis: a double blind, placebo-controlled, randomized clinical trial, Rheumatology (Oxford), 2015, 10.1093/rheumatology/kev426.

22. Wuschech H., von Hehn U., Mikus E., Funk R.H. Effects of PEMF on patients with osteoarthritis: Results of a prospective, placebo-controlled, double-blind study, Bioelectromagnetics, 2015, Vol. 36, No. 8, pp. 576-585.

23. Li S., Yu B., Zhou D. et al. Electromagnetic fields for treating osteoarthritis, Cochrane Database Syst. Rev., 2013, PMID: 2433843

24. Goksen N., Calis M., Dogan S. et al. Magnetic resonance therapy for knee osteoarthritis: a randomized, double blind placebo controlled trial, Eur. J. Phys. Rehabil., 2016, PMID: 26799573

25. Ponomarenko G.N. Chastnaya fizioterapiya: Uchebnoye posobiye (Private Physiotherapy: A Training Manual), M.: Meditsina, 2005, $744 \mathrm{p}$.

26. Kulchitskaya D.B., Konchugova T.V., Lukianova T.V., Gushchina N.V. Obosnovaniye primeneniya vysokointensivnoy lazernoy terapii dlya lecheniya patsiyentov s gonartrozom (Rationale for the use of high-intensity laser therapy for the treatment of patients with gonarthrosis), Voprosy kurortologii. fizioterapii i lechebnoy fizicheskoy kultury, 2015, No. 1, pp. 23-26.

27. Stiglić-Rogoznica N., Stamenković D., Frlan-Vrgoc L. et al. Analgesic effect of high intensity laser therapy in knee osteoarthritis, Coll. Antropol., 2011, No. 35, Suppl 2, pp. 183-185.

28. Kheshie A.R., Alayat M.S., Ali M.M. High-intensity versus low-level laser therapy in the treatment of patients with knee osteoarthritis: a randomized controlled trial, Lasers Med. Sci., 2014, No. 29, Vol. 4, pp. 1371-1376.

29. Kędzierski T., Stańczak K., Gworys K., et al. Comparative evaluation of the direct analgesic efficacy of selected physiotherapeutic methods in subjects with knee joint degenerative disease - preliminary report, Ortop. Traumatol. Rehabil., 2012, Vol. 14, No. 6, pp. 537-544.

30. Bjordal J.M., Johnson M.I., Lopes-Martins R.A. et al. Short-term efficacy of physical interventions in osteoarthritic knee pain. A systematic review and meta-analysis of randomised placebo-controlled trials, BMC Musculoskelet. Disord., 2007, No. 8, pp. 51.

31. Cherian J.J., Harrison P.E., Benjamin S.A., Bhave A., Harwin S.F., Mont M.A. Do the Effects of Transcutaneous Electrical Nerve Stimulation on Knee Osteoarthritis Pain and Function Last?, J. Knee Surg., 2015, DOI: 10.1055/s-0035-1566735

32. Zeng C., Li H., Yang T., et al. Electrical stimulation for pain relief in knee osteoarthritis: systematic review and network metaanalysis, Osteoarthritis Cartilage, 2015, Vol. 23, No. 2, pp. 189-202.

33. Ponomarenko G.N. Fizicheskaya i reabilitatsionnaya meditsina: Natsionalnoye rukovodstvo (Physical and Rehabilitation Medicine: National leadership), M.:GEOTAR-Media, 2016, $688 \mathrm{p}$

34. 3Vaz M.A., Baroni B.M., Geremia J.M. et al. Neuromuscular electrical stimulation (NMES) reduces structural and functional losses of quadriceps muscle and improves health status in patients with knee osteoarthritis, J. Orthop. Res., 2013, Vol. 31, No. 4, pp. 511-516.

35. Babaskin D.V., Chuntomov P.N., Pozhidaev I.A., et al. The application of sinusoidal modulated current electrophoresis of a phytopreparation for the rehabilitation of patients with knee joint osteoarthrosis, Vopr. Kurortol. Fizioter. Lech. Fiz. Kult., 2011, No. 6, pp. 24-28.

36. Yildiz S.K., Özkan F.Ü., Aktaş I. et al. The effectiveness of ultrasound treatment for the management of knee osteoarthritis: a randomized, placebo-controlled, double-blind study, Turk. J. Med. Sci., 2015, Vol.45, No. 6, pp. 1187-1191.

37. Yıldırım M.A., Uçar D., Öneş K. Comparison of therapeutic duration of therapeutic ultrasound in patients with knee osteoarthritis, J. Phys. Ther. Sci., 2015, Vol. 27, No. 12, pp. 3667-3670.

38. Loyola-Sánchez A., Richardson J., MacIntyre N.J. Efficacy of ultrasound therapy for the management of knee osteoarthritis: a systematic review with meta-analysis, Osteoarthritis Cartilage, 2010, Vol. 18, No. 9, pp. 1117-11126.

39. Branco M., Rego N.N., Silva P.H., et al. Bath thermal waters in the treatment of knee osteoarthritis: a randomized controlled clinical trial, Eur. J. Phys. Rehabil. Med., 2016, PMID:26899038

40. Razumov A.N., Puriga A.O., Yurova O.V. Rezultaty kompleksnogo primeneniya ekstrakorporalnoy udarno-volnovoy terapii i radonovykh vann $\mathrm{v}$ vosstanovitelnom lechenii patsiyentov $\mathrm{s}$ gonartrozom (The results of the integrated application of extracorporeal shock wave and radon baths in regenerative treatment of patients with gonarthrosis), Voprosy kurortologii, fizioterapii i lechebnoy fizicheskoy kultury, 2015, T. 92, No. 5, pp. 35-39.

41. Chao Y.H., Tsuang Y.H., J.S. Sun., et al. Effects of shock waves on tenocyte proliferation and extracellular matrix metabolism, Ultrasound Med. Biol., 2008, Vol. 34, No. 5, pp. 841-852.

42. Chen Y.J., Wang C.J., Yang K.D., et al. Extracorporeal shock waves promote healing of collagenase-induced Achilles tendinitis and increase TGF-beta1 and IGF-I expression, J. Orthop. Res., 2004, Vol. 22, No. 4, pp. 854-861.

43. Ochiai N. Extracorporeal shock wave therapy improves motor dysfunction and pain originating from knee osteoarthritis in rats, Osteoarthritis Cartilage, 2007, Vol. 15, No. 9, pp. 1093-1096.

44. Tamma R., dell'Endice S., Notarnicola A. et al. Extracorporeal shock waves stimulate osteoblast activities, Ultrasound Med. Biol., 2009, Vol. 35, No. 12, pp. 2093-100. 
45. Waugh C.M., Morrissey D., Jones E. et al. In vivo biological response to extracorporeal shockwave therapy in human tendinopathy, Eur. Cell Mater., 2015, Vol. 29, pp. 268-80.

46. Kam-Fai Tam, Wing-Hoi Cheung, Kwong-Man Lee, et al. Shockwave Exerts Osteogenic Effect on Osteoporotic Bone In an Ovariectomized Goat Model, Ultrasound in Medicine \& Biology, 2009, Vol. 35, pp. 1109-1118.

47. Kawcak C.E., Frisbie D.D., McIlwraith C.W. Effects of extracorporeal shock wave therapy and polysulfated glycosaminoglycan treatment on subchondral bone, serum biomarkers, and synovial fluid biomarkers in horses with induced osteoarthritis, $A m$. $J$. Vet. Res., 2011, Vol. 72, No. 6. - P. 772-779.

48. Zhao Z., Ji H., Jing R. et al. Extracorporeal shock-wave therapy reduces progression of knee osteoarthritis in rabbits by reducing nitric oxide level and chondrocyte apoptosis, Arch. Orthop. Trauma Surg., 2012, Vol. 132, pp. 1547-1553.

49. Zhao Z., Jing R., Shi Z. Efficacy of extracorporeal shockwave therapy for knee osteoarthritis: a randomized controlled trial, Journal of surgical research, 2013, Vol. 185, pp. 661-666.

50. Kim Jin-Hong, Ja-Young Kim, Cheol-Min Choi The Dose-Related Effects of Extracorporeal Shock Wave Therapy for Knee Osteoarthritis, Ann. Rehabil. Med., 2015, Vol. 39, No. 4, pp. 616-623.

51. Shavianidze G.O., Lapanashvili L.V., Myshechnaya kontrpulsatsiya v vosstanovitelnom lechenii bolnykh osteoartrozom (Muscular counterpulsation in the regenerative treatment of patients with osteoarthritis), Voprosy kurortologii, fizioterapii $i$ lechebnoy fizicheskoy kultury, 2006, No. 5, pp. 11-14.

52. Gungen G.O., Ardic F., Findikoglu G., Rota S. Effect of mud compress therapy on cartilage destruction detected by CTX-II in patients with knee osteoarthritis, J. Back Musculoskelet. Rehabil., 2015, Vol. Preprint, No. Preprint, pp.1-9.

53. Sidorov V.D., Pershin S.B. Reabilitatsiya patsiyentov s osteoartrozom (Rehabilitation of patients with osteoarthritis), Voprosy kurortologii, fizioterapii i lechebnoy fizicheskoy kultury, 2015, No. 5, pp. 28-34.

54. Young Geun Park, Bum Sun Kwon, Jin-Woo Park, et al. Therapeutic Effect of Whole Body Vibration on Chronic Knee Osteoarthritis, Ann. Rehabil. Med., 2013, Vol. 37, No. 4, pp. 505-515.

55. Wang P., Yang L. , Li H. , et al. Effects of whole-body vibration training with quadriceps strengthening exercise on functioning and gait parameters in patients with medial compartment knee osteoarthritis: a randomised controlled preliminary study, Physiotherapy, 2016, Vol. 102, No.1, pp. 86-92. 